\title{
As modernas relações entre direito civil e direito constitucional: a tutela da pessoa em foco
}

\author{
Modern relationships between civil law and \\ constitutional law: the protection of the person \\ in focus
}

Wesllay Carlos Ribeiro*

\section{Resumo}

A sociedade contemporânea é marcada pela complexidade nas relações, pela globalização, pela massificação do consumo, pela explosão demográfica, pelo pluralismo e pela necessidade de um Direito dinâmico e que busque alcançar os seus fins. Nesse sentido são crescentes na literatura mundial e brasileira estudos que buscam analisar a aproximação do Direito Privado com o Direito Constitucional. Neste estudo de revisão bibliográfica pretende-se analisar as modernas relações entre Direito Constitucional e Direito Civil tendo por foco os direitos da personalidade. Verifica-se que tanto nos direitos da personalidade como nos direitos fundamentais há identificação de sua essência na tutela e promoção da pessoa humana.

Palavras-chave: Direito privado. Direito constitucional. Direitos da personalidade. Direitos fundamentais.

\section{Abstract}

Contemporary society is marked by complexity in relationships, by globalization, mass consumption, the population explosion, pluralism and the need for a dynamic law and seek to achieve their ends. In this sense the Brazilian and foreigner studies are growing forward to analyze the approach of Private Law with Constitutional Law literature. In this bibliographic review we intend to

Professor da Universidade Federal de Alfenas - UNIFAL/MG, Campus Varginha, Instituto de Ciências Sociais Aplicadas. Varginha - MG - Brasil. Email: wesllay.ribeiro@gmail.com 
analyze modern relationships between Constitutional Law and Civil Law with focus on personality rights. It is found that both personality rights as fundamental rights have identification in the protection and promotion of the human person.

Keywords: Private law. Constitutional law. Personality rights. Fundamental rights.

\section{Introdução}

Desde o Estado Liberal Burguês, passando pelo Estado Social, até o Estado Democrático, as Constituições pelo mundo passaram por um processo de crescente fortalecimento e desenvolvimento. No Brasil, esse evolver foi permeado por documentos democráticos e autoritários que, de certa forma, deixaram o debate mais profundo e concretizador sobre o constitucionalismo, à margem do que ocorreu em outros países. Eis uma razão pela qual considera-se o movimento constitucional brasileiro como de modernidade tardia.

Assim foi que a Constituição da República Federativa do Brasil, de 05 de outubro de 1988, trouxe à lume uma nova acepção ao ordenamento jurídico brasileiro, focada em novos fundamentos Entretanto, uma Constituição não nasce Constituição, mas sim se faz Constituição. Esse se fazer Constituição se deve em boa medida à forma pela qual os atores do cenário jurídico irão recepcionar, interpretar e aplicar a Lei Maior de 1988, motivo por si só para demonstrar a relevância de estudos sobre o tema. Salienta-se que no movimento constitucional contemporâneo duas correntes coexistem: a primeira, denominada dogmática da razão do Estado, que vê o Direito Constitucional como qualquer outro domínio do Direito, prende-se a conceituações e interpretações retrospectivas à ordem constitucional instaurada pela Constituinte de 1988 e objetiva a legitimação da atuação do Poder Político onde o Estado assume absoluta centralidade. A segunda corrente, dogmática constitucional emancipatória, foca a leitura da Constituição sob a noção de dignidade da pessoa humana. Nessa perspectiva, procura-se não só conhecer 
o direito, mas também compreender como ele é operado e como se concretiza. O foco, nessa perspectiva, deixa de ser o Estado e passa a ser a pessoa humana, sua promoção e realização. Outrossim, este estudo busca analisar a aproximação do Direito Privado com o Direito Constitucional, tendo por foco a pessoa humana. O estudo será permeado pelo exame da noção de dignidade da pessoa humana e da impossibilidade de reificação da pessoa, perscrutando ainda como a moderna concepção dos direitos fundamentais e dos direitos da personalidade contribuem para uma visão mais abrangente da tutela e promoção da pessoa.

\section{A dignidade da pessoa humana}

Aconcretização da dignidade da pessoa humana como fundamento do Direito encerra a necessidade de que este último seja atuante e que se identifique com os postulados culturais inscritos na personalidade.

A luta pelos direitos humanos e, em geral, pela defesa e promoção da dignidade humana, não é um mero exercício intelectual, é uma prática que resulta de uma entrega moral, afectiva e emocional ancorada na incondicionalidade do inconformismo e da exigência de acção. Tal entrega só é possível a partir de uma identificação profunda com postulados culturais inscritos na personalidade e nas formas básicas de socialização. (SANTOS, 2008).

Segundo Comparato (2008), o conceito moderno de dignidade humana encontra os seus primeiros passos na doutrina cristã e no pensamento clássico. Tanto no Antigo como no Novo Testamento, é possível encontrar referência de que o homem foi criado à imagem e semelhança de Deus, daí o pensamento de Santo Tomás de Aquino entender que a dignidade é inerente ao homem. (SARLET, 2007). A expressão dignidade vem do latim dignus que significa aquele que merece estima e honra, aquele que é importante e sua utilização sempre correspondeu à espécie humana. (MORAES, 2007). A esse respeito, Arendt (2008) propõe uma re-significação do homem que se encaixa 
em tempo de pós-modernidade ${ }^{1}$, uma vez que existe uma complicação própria do ser humano de se definir, porque sempre que se pensa em alguém (outro ser humano), inevitavelmente vem ao pensamento o que esse alguém é, esquecendo o que existe de singular e específico na própria essência humana.

Se a dignidade teve sua origem na doutrina cristã, a Kant (2005) é atribuída a sua secularização, que é transportada da noção do sagrado para ser construída em bases racionais, compreendendo a divisão entre coisas que têm preço e pessoas que têm dignidade. Assim é que se desenvolve o pensamento pelo qual o homem nunca seja visto como meio para alguma finalidade ou objetivo, mas sempre como um fim em si mesmo. A esse respeito, a premissa é a de que os seres racionais, por natureza, são fins em si; portanto, um valor absoluto. (MORAES, 2007). O pensamento contemporâneo, fundado na proposição Kantiana, é adotado nas principais teorias sobre dignidade humana e constitui o ponto nodal da completa negação da coisificação do homem. (SARLET, 2007).

Assim é que a teoria constitucional, inaugurada pela constituinte de 1988, privilegiou o princípio da dignidade humana como fonte do ordenamento jurídico vigente.

A dignidade da pessoa humana, hoje, não é mais um conceito transcendental, expressão de uma necessidade metafísica. Expressa isso sim, uma imprescindibilidade da condição humana. A sua concretização é uma imposição dos tempos atuais do grau de desenvolvimento das sociedades, do nível de aprofundamento da investigação científica a que se propõe a nascente dogmática dos direitos fundamentais. (JACHINTO, 2006, p. 25).

A dignidade humana passou então a ser reconhecida como valor supremo no texto constitucional e princípio que deve regular a ordem econômica, política, social e cultural.

Sobre o termo pós-modernidade ver entre outros: Amaral (2003, p. 61-77); Hironaka (2003, p. 93-114) e Travessoni (2011, p. 319-324). 
Poderíamos até dizer que a eminência da dignidade da pessoa humana é tal que é dotada ao mesmo tempo da natureza de valor supremo, princípio constitucional fundamental e geral que inspira a ordem jurídica. Mas a verdade é que a Constituição lhe dá mais do que isso, quando a põe como fundamento da República Federativa do Brasil constituída em Estado Democrático de Direito. Se é fundamento é porque se constitui num valor supremo, num valor fundante da República, da Federação, do país, da Democracia e do Direito. Portanto, não é apenas um princípio da ordem jurídica, mas o é também da ordem política, social, econômica e cultural. Daí sua natureza de valor supremo, porque está na base de toda a vida nacional. $[\ldots]$

Em conclusão, a dignidade da pessoa humana constitui um valor que atrai a realização dos direitos fundamentais do Homem, em todas as suas dimensões; e, como a democracia é o único regime político capaz de propiciar a efetividade desses direitos, o que significa dignificar 0 Homem, é ela que se revela como o seu valor supremo, o valor que o dimensiona e humaniza. (SILVA, 2007, p. 149).

Entretanto, não obstante o valor conferido à dignidade da pessoa humana, ela não se concretiza como um remédio para todos os males. (SARLET, 2007). Essa é a razão pela qual se faz necessária uma melhor análise do que se pode entender como dignidade humana.

Nesse sentir, Sarlet (2007) relata que a complexidade do ser humano e das suas relações, para que se possa ter uma melhor noção de dignidade humana, dada a heterogeneidade e a riqueza da vida que integra um conjunto de fundamentos e de manifestações. Esse conjunto, mesmo que apresentando diferenças, tem um ponto em comum e guarda um núcleo essencial de compreensão do que realmente é a dignidade da pessoa humana.

Essa concepção plural de dignidade humana não quer significar que não haja aplicação real e imediata do princípio como norma criadora e protetora de direito no mundo fático; pelo contrário, é consenso entre 
os doutrinadores ${ }^{2}$ que a dignidade da pessoa humana tem aplicação efetiva e direta na realidade das pessoas.

Nesse sentido, uma das dimensões da dignidade se relaciona com a questão ontológica, aceita desde a época clássica, ao postular que a dignidade é qualidade intrínseca e irrenunciável do ser humano e, por isso, faz parte da essência da espécie humana, não se podendo ganha-la ou perdê-la. (JACHINTO, 2006). Não se trata de algo que se pode pedir a alguém; também e certamente, não é algo perecível ou que pode variar de grau durante a vida de forma que, em certos momentos, a pessoa tenha mais ou menos dignidade de acordo com a sua própria percepção, idade ou estado mental. A dignidade é algo imutável e perene, inerente à vida humana. Embora não possa ser perdida ou ganhada, é certo que pode ser violada e, portanto, deve ser protegida.

Talvez por isso a Declaração Universal dos Direitos Humanos, adotada e proclamada pela Resolução 217 A (III) da Assembleia Geral das Nações Unidas, de 10 de dezembro de 1948, estabeleça no seu art. $1^{\circ}$ que "todas as pessoas nascem livres e iguais em dignidade e direitos. São dotadas de razão e consciência e devem agir em relação umas às outras com espírito de fraternidade". (ONU, 2009).

Por tal razão, Sarlet (2007) afirma que a dignidade não existe apenas onde é reconhecida pelo Direito e, na medida em que este a reconheça, já que constitui um dado prévio, preexistente e anterior a toda experiência especulativa.

A evolução da premissa ontológica da dimensão da dignidade humana reforça a compreensão que a noção Kantiana ainda é considerada. Decorre daí que todo ser humano tem igual dignidade, pouco importando que ele tenha ou não percepção da mesma. (SARLET, 2007).

2 Ver entre outros: Jacintho (2006); Sarlet (2007). 
Para além dessa concepção ontológica da dignidade humana, o homem também deve ser pensado em sua intensa relação social, como ser que vive em sociedade. (COMPARATO, 2001). Assim, é possível falar também de uma dignidade que se dá em uma concepção intersubjetiva, uma vez que por serem as pessoas todas iguais em dignidade, se obrigam a exercer o direito à dignidade de forma interrelacional, respeitando-se na medida em que a igualdade torna a todos titulares de um mesmo direito. (JACHINTO, 2006). Sarlet (2007) adverte, entretanto, que essa inter-relação não significa que se possa sacrificar a dignidade de determinada pessoa em prol da comunidade. Essa visão comunitária da dignidade se operará também na relação dos indivíduos com o Estado, gerando, por sua vez, uma dimensão política da dignidade. Desse modo, cada um e todos passam a ser credores e devedores de uma igual proteção perante o Estado.

Assim é que haverá necessidade de proteção da dignidade humana sempre que a pessoa for reduzida em sua condição humana ou sempre que for rebaixada a objeto, a mero instrumento, tratada como uma coisa, em outras palavras, sempre que a pessoa venha a ser descaracterizada e desconsiderada como sujeito de direitos. (SARLET, 2007). Partindo desse pressuposto, Moraes (2003, p.85) apresenta o que chama de substrato material da dignidade e que se fundamenta em quatro bases:

i) o sujeito moral (ético) reconhece a existência de outros como sujeitos iguais a ele; ii) merecedores do mesmo respeito à integridade psicofísica de que é titular; iii) é dotado de vontade livre, de autodeterminação; iv) é parte do grupo social, em relação ao qual tem garantia de não vir a ser marginalizado.

Tais bases, ainda segundo a autora, funcionariam como corolários para os princípios jurídicos da igualdade, da integridade física e moral - psicofísica -, da liberdade e da solidariedade. Na busca de maior clareza para delimitar o que seja dignidade humana define como núcleo essencial - como centro de irradiação e proteção da dignidade humana - a possibilidade de que se tem: 
[a dignidade humana] como direito material apresenta um núcleo essencial cujos elementos integradores são - sem exclusão de outros que possam ser assim apresentados - a liberdade de crença, e os direitos à saúde, educação, moradia e alimentação. (JACHINTO, 2006, p. 140).

Barcellos (2005) propõe que a dignidade humana propicie um mínimo existencial à pessoa que é formado pelo direito à educação, à assistência aos desempregados, à saúde e o acesso à justiça. Sarlet (2007, p. 62) inclui nesse rol os direitos de nacionalidade e de cidadania e conceitua a dignidade humana, sob o cerne da vedação da coisificação do ser humano, da seguinte forma:

\begin{abstract}
tem-se por dignidade da pessoa humana a qualidade intrínseca e distintiva reconhecida em cada ser humano que o faz merecedor do mesmo respeito e consideração por parte do Estado e da comunidade, implicando, neste sentido, um complexo de direitos e deveres fundamentais que assegurem a pessoa tanto contra todo e qualquer ato de cunho degradante e desumano, como venham a the garantir as condições existenciais mínimas para uma vida saudável, além de propiciar e promover sua participação ativa e co-responsável nos destinos da própria existência e da vida em comunhão com os demais seres humanos.
\end{abstract}

Essa noção de dignidade da pessoa humana focada na proteção da sua integridade, embora não possa ser tida como universal e única, e ainda levando em consideração a delimitação de seu núcleo, denota a evidente importância que a pessoa ocupa no ordenamento jurídico.

\title{
2 Constituição e direito privado
}

As relações privadas existem desde que as pessoas iniciaram o processo de sociliazação. Hironaka (2003) afirma que o Direito é tão antigo como a própria história dos homens e que o Direito Civil pode ser dividido em quatro grandes fases históricas: partindo do Direito Romano, passando pelo Direito Medieval e pelo Direito Moderno, até chegar ao que hoje pode ser denominado como Direito Contemporâneo. 
Ao longo do tempo, o Direito Civil sempre esteve relacionado ao locus normativo privilegiado do individuo sendo o ramo do Direito que mais se mantinha distante do Direito Constitucional, chegando mesmo a uma contraposição como constituição do homem no Direito Moderno. (LOBO, 2003). Esse distanciamento fez com que por um longo período a constituição fosse tema ausente na doutrina civilista. A coerência do Direito Civil se formava em um sistema interno e próprio fundado em uma lógica dedutiva que se bastava para resolver as questões postas a seu exame e seus próprios conflitos normativos. O Direito Civil era a seara da segurança jurídica e da estabilidade nas relações. Nesse contexto, na modernidade, a Constituição fundamentada em princípios e valores era vista como algo distante da realidade dos eventos práticos tratados na sistemática civilista. "A Constituição não falava a linguagem dos Códigos, e os civilistas, para o bem ou para o mal, foram forjados na escola dos Códigos". (BRAGA NETTO, 2004, p. 189).

No Brasil, esse evolver não foi diferente, uma vez que o Direito $\mathrm{Civil}^{3}$ resistiu a cinco Constituições, entre documentos autoritários e democráticos, sem que fossem introduzidas grandes alterações em sua estrutura monolítica. Não se acreditava que as alterações no texto constitucional, vistas um tanto quanto distantes da realidade das relações do Código Civil, pudessem causar alguma mudança, chegando ao ponto que "talvez não fosse exagerado afirmar que havia uma recíproca repulsa entre Direito Civil e a Constituição". (BRAGA NETTO, 2004, p. 190).

Nesse contexto, o Código Civil era o centro orbital ao redor do qual gravitava o Direito Privado. O paradigma de então era o do direito moderno estabelecido nas bases do Estado Liberal cujo patrimonialismo era a marca mais relevante. Vigorava "a concepção formal do direito, ou formalismo jurídico, segundo a qual o direito se reduziria à norma, donde o sinônimo de normativismo". (AMARAL, 2003, p. 71).

Assim considerado o período inaugurado após a publicação do Código Civil de 1916, vez que antes a legislação ainda era atrelada a herança legislativa lusitana. 
Atualmente, entretanto, como ressalta Canotilho $(2008$, p. 192) "é crescente o número de trabalhos dedicados às relações entre o direito constitucional e o direito civil". Essa busca de aproximação entre o Direito Civil e a Constituição se deve em boa parte às profundas alterações sociais da época atual. A sociedade contemporânea é marcada pela complexidade nas relações, pela globalização, pela massificação do consumo, pela explosão demográfica, pelo pluralismo e, "dado o notável desenvolvimento científico e tecnológico das últimas décadas, é reconhecidamente a sociedade do conhecimento e da informação".

Essa realidade social "já não é própria para a sistematização e as grandes sínteses, mas sim para a análise crítica e a desconstrução dos sistemas vigentes, sob a égide de princípios jurídicos que dão maior eficácia, garantia e legitimidade à matéria privada". (AMARAL, 2003, p. 63).

Denninger, segundo Moraes (2007), afirma que se notam diferenças acentuadas entre o Direito da época das Luzes e da Revolução Francesa e o Direito atual levando ao "fim da razão prática universal, daquela razão, fonte privilegiada do Direito Privado, a que se referiu Kant, assinalando-se aí o início de uma nova era: uma era de incertezas, de instabilidades". Dentre as diversas circunstâncias que contribuíram para essa era de incertezas, Moraes (2007) destaca a impossibilidade de conhecimento sobre os efeitos da tecnologia; a chamada explosão de ignorância, efeito da enorme quantidade de informações disponíveis nos modernos meios de comunicação, levando a um leque cada vez maior de temas sem solução, o que incrementa a percepção da ignorância e da incerteza sobre as coisas; e, por fim, o fato de que uma maior acumulação de conhecimento "sobre o mundo não aumentou a sabedoria do mundo, da pessoa em relação a si própria, aos demais, à natureza."

Contrapôs-se o mundo da segurança idealizado pelo jurista do Código Civil, no Estado Moderno, com a época atual, própria da instabilidade, à era das incertezas. 
A essa marcha de alterações no cenário social, soma-se a repulsa aos horrores cometidos durante a Segunda Grande Guerra o que provocou, conforme assevera Piovesan (2000), a necessidade da reconstrução dos Direitos Humanos que passam a se destinar à efetivação dos direitos relacionados à dignidade humana. Piovesan (2006) ainda esclarece que a concepção sobre Direitos Humanos foi radicalmente alterada, passando a ser marcada pela universalidade e pela indivisibilidade, já que os direitos humanos devem ser considerados na sua inter-relação na esfera civil, política, social, econômica e cultural.

Assim, com o fortalecimento das Constituições dos Estados Democráticos, ocorre um fenômeno em que há a interpenetração entre Direito Público e Privado, fazendo com os princípios fundamentais deste último sejam transportados para a seara constitucional que, por sua vez, passam a ser lidos sob a égide de seus preceitos. Essa dinâmica de retroalimentação compõe um processo de interferências mútuas que, entretanto, estabelece como ápice do sistema a normativa constitucional. (SARMENTO, 2008). Os princípios, base das relações privadas, agora princípios Constitucionais, deslocam o centro do Direito Privado para a Constituição e trazem como consequência a necessidade da "reconstrução do sistema do Direito Privado". (MORAES, 2007).

Segundo Braga Netto (2004), a quebra das barreiras entre Direito Público e Privado à luz da Constituição suscitou expressiva alteração na "compreensão metodológica: ao direito civil, como um todo - e não apenas a setores seus, como o sistema de consumo - cabe coibir abusos, reequilibrar posições, estabelecer limites." No mesmo sentido, Sarmento (2008) afirma que o acolhimento pela Constituição de temas que, no passado, eram tratados pelo Código Civil, importa em uma releitura do Direito Civil à luz da Constituição.

Nesse processo de reconstrução conceitual do Direito Privado, para Hironaka (2003,p. 107), "o individuo liberal que triunfara no século anterior, por influência, ainda, do evolver oitocentista, cede lugar ao personalismo ético como valor político-social fundante e legitimador, a pessoa humana passa a ser o ponto central do direito." No Direito Civil 
Liberal, a propriedade era o valor necessário de realização da pessoa; sobre o patrimônio gravitavam os interesses privados. De acordo com Lobo (2003, p. 206), "o desafio que se coloca aos civilistas é a capacidade de ver as pessoas em toda a sua dimensão ontológica e, através dela, seu patrimônio. Impõe-se a materialização dos sujeitos de direitos, que são mais que apenas titulares de bens." Busca-se estabelecer a preeminência da pessoa, nas relações civis, tida como condição da adequação do direito à realidade e aos fundamentos constitucionais. O Direito Civil altera o seu foco do patrimônio para a pessoa, sua proteção e realização. Como bem expõe Fachin (2008), o significado do significante se modifica, ou seja, há uma releitura dos institutos civilistas de forma que o significante no Direito Civil ganha outro significado: a pessoa. Assim é que

O legislador constituinte, de maneira categórica, pretende evitar que a iniciativa econômica privada possa ser desenvolvida de maneira prejudicial à promoção da dignidade da pessoa humana e à justiça social. Rejeita, igualmente, que os espaços privados, como a família, a empresa e a propriedade, possam representar uma espécie de zona franca para a violação do projeto constitucional. Daí ter regulamentado, sem cerimônia, e malgrado as violentas e tão mal-humoradas críticas que sofreu, todas as relações jurídicas de direito privado.

\section{$[\ldots]$}

Constitucionalização do Direito Civil, em uma palavra, não é apenas um adjetivo a colorir a dogmática forjada pela escola da exegese, que pode ser a cada momento purificada ou atualizada, mas uma alteração profunda da ordem pública, a partir da substituição dos valores que permeiam o direito civil, no âmbito do qual a pessoa humana passa a ter prioridade absoluta. (TEPEDINO, 2003, p. 127 e 188).

Aopção prioritária pela dignidade da pessoa humana realizada pela Constituinte de 1988 objetivou também o ordenamento jurídico privado e fez com que a "perspectiva jurídica tomasse para si o papel garantidor da transição em direção ao personalismo, ausente em outros momentos 
históricos quando a Igreja, o Estado e o Exército tiveram alçadas de poder em relação às escolhas individuais." (MORAES, 2007,p. 19) Nessa nova ordem jurídica, "a aferição da constitucionalidade de um diploma legal, diante da repersonalização imposta a partir de 1988, deve levar em consideração a prevalência da proteção da dignidade humana em relação às relações jurídicas patrimoniais". (FACHIN, 2000, p.132).

É nesse sentido que Braga Netto (2004, p. 199) escreve que as chaves da leitura do Direito Civil estão na Constituição. "É uma progressiva aproximação entre campos antes opostos que redimensionará, dialeticamente, os futuros conteúdos normativos do direito civil, permitindo-Ihe uma salutar depuração das excessivas doses de patrimonialidade que ainda carrega."

Assim é que, para Lorenzetti (1998, p. 253), “o Direito Privado é Direito Constitucional aplicado, pois nele se detecta o projeto de vida em comum que a Constituição tenta impor; o Direito Privado representa os valores sociais de vigência efetiva". É essa aplicação do Direito Constitucional nas relações civis, especialmente para o tema em estudo na relação entre direitos fundamentais e direitos da personalidade e seus reflexos sobre a nova teoria da responsabilidade civil que se passará a analisar.

\section{Os direitos da personalidade}

A Lei $n^{\circ} 10.406 / 2002$ destinou, no Título I - das pessoas naturais, o Capítulo II, artigos 11 a 21, aos Direitos da Personalidade, trata-se de inovação normativa em relação ao Código Civil anterior que não dedicou um capítulo próprio à matéria. (BRASIL, 2002).

Sendo tema relativamente novo, há divergências sobre diversos pontos, a começar pela nomenclatura que passa por expressões como: direitos do homem, direitos fundamentais da pessoa, direitos humanos, direitos inatos, direitos essenciais da pessoa, liberdades fundamentais e especialmente direitos da personalidade. (BITTAR, 2008). 
Para Bittar (2003), os direitos da personalidade são "poderes que o ser exerce sobre si mesmo (o homem como objeto de direito), têm como integrante de seu contexto qualidades ou atributos, físicos, morais ou intelectuais, da pessoa, reconhecidos pelo ordenamento jurídico." Sob esse aspecto, os direitos da personalidade seriam definidos como os próprios da pessoa e aqueles decorrentes da projeção da pessoa nas suas relações com o mundo, como o nome, a honra, o direito autor, entre outros.

São, ainda, para Bittar e Bittar Filho (2008, p. 17), direitos inatos da pessoa, "em função de sua própria estruturação física, mental e moral. Daí são dotados de certas particularidades, que lhes conferem posição singular no cenário dos direitos privados". Nessa concepção, a pessoa é a um só tempo, sujeito e objeto dos direitos, tendo a coletividade como sujeito passivo universal, decorrendo o seu caráter absoluto e a oponibilidade erga omnes. Representam o direito do homem sobre si mesmo, jura in se ipsum.

De Cupis (2004, p. 24) entende que todos os direitos que visam dar conteúdo à personalidade podem ser chamados de direitos da personalidade. Trata-se dos direitossubjetivos, "cujafunção, relativamente à personalidade, é especial, o minimum necessário e imprescindível ao seu conteúdo". Os direitos da personalidade seriam "certos direitos sem os quais a personalidade restaria uma susceptibilidade completamente irrealizada, privada de todo o valor concreto", são os direitos essenciais que compõem a cerne da personalidade.

A personalidade, segundo Fiúza e Gama (2009, p. 112) possui duas acepções, uma subjetiva e outra objetiva. Pela primeira, personalidade, "é atributo jurídico conferido ao ser humano e a outros entes (pessoas jurídicas), em virtude do qual se tornam capazes, podendo ser titulares de direito e deveres nas relações jurídicas." Nessa acepção, a pessoa é elemento subjetivo da estrutura das relações jurídicas. Já na acepção objetiva, "a personalidade é um conjunto de atributos e características da pessoa humana, considerada objeto de proteção do ordenamento jurídico. Assim, enquanto sujeito, a pessoa (personalidade) não pode ser 
objeto em relação de que é titular." Entretanto, como valor, decorrente do conjunto de atributos a personalidade, passa a ser objeto da tutela jurídica. Pela acepção objetiva, visa-se à proteção e à promoção da pessoa humana e de sua dignidade e, por isso mesmo, é a que melhor se enquadra no ordenamento civil-constitucional vigente.

Ainda sob o plano de justificação dos direitos da personalidade, há teorias que negam essa categoria de direito e ainda, para aquelas que o admitem, há certo debate sobre se eles se estabelecem por meio da chamada teoria monista ou por outra vertente denominada pluralista.

Segundo as teorias negativas não é possível se falar sobre direito da personalidade uma vez que a pessoa não pode ser objeto de direitos. Para essas teorias, "a vida, a honra, a saúde não pertencem à categoria do ter, mas do ser, o que as torna incompatíveis com a categoria dos direitos subjetivos". (FIÚZA; GAMA, 2009, p 111).

Por outro lado admitindo a existência dos Direitos da personalidade, há ainda que se diferenciar a teoria monista e a teoria pluralista. Assim, de acordo com a teoria monista, "quando se fala em direito à vida, à honra, à saúde, não se está referindo a vários direitos distintos da personalidade, mas a desdobramentos de um único direito geral". (FIÚZA; GAMA, 2009, p. 118). A pessoa é una e seus interesses estão ligados. Assim, justifica-se um direito geral de personalidade que confere uma tutela genérica à personalidade e a suas exteriorizações na coletividade.

Pinto (2000, p. 69) afirma que a "concepção que defende a existência de um direito geral de personalidade triunfou, na maioria das ordens jurídicas, em particular sobre o numerus clausus de direitos de personalidade, mesmo onde ele inicialmente foi aceito". O direito geral de personalidade figura com um "direito-quadro" onde se emolduram várias normas que visam à proteção da pessoa.

Já segundo a teoria pluralista, os direitos da personalidade são vários e cada um busca a satisfação de uma necessidade. "Assim, embora a pessoa seja una, suas necessidades são diversas. A 
necessidade de viver é diferente de viver com honra; a necessidade de um nome é diferente da necessidade de viver com saúde e assim por diante". (FIÚZA; GAMA, 2009, p. 118).

No sistema jurídico civilista brasileiro foi adotada a teoria monista. Entretanto, como adverte Tepedino, Barboza e Moraes (2004, p.33), em razão da consagração do princípio da dignidade da pessoa pela normativa Constitucional, a controvérsia entre as teorias monista e pluralista foi superada, isso porque "ambas revelam-se insuficientes, mostrandose vinculadas ao paradigma dos direitos subjetivos patrimoniais, em especial ao modelo de direito de propriedade."

Por essa razão Moraes (2007, p. 117) entende que não há mais possibilidade de "se discutir sobre a enumeração taxativa ou exemplificativa dos direitos da personalidade, porque se está em presença, a partir do princípio constitucional da dignidade, de uma cláusula geral de tutela da pessoa humana." Assim, os direitos da personalidade estão garantidos pelo princípio constitucional da dignidade humana e em seu núcleo estão a igualdade, a integridade psicofísica, a liberdade e a solidariedade.

Para Fiúza e Gama (2009, p. 120), a diferença entre a teoria monista e a cláusula geral da personalidade se dá pelo fato que a teoria monista "considera a personalidade com fonte de um direito geral e originário de personalidade. Quando este direito for violado em alguma situação existencial [...] o ordenamento jurídico socorre o prejudicado." Já para "os adeptos da cláusula geral de tutela da personalidade, a personalidade seria um valor, ou o valor supremo de uma sociedade democrática, do qual decorreria não só a proteção da dignidade humana, mas também a promoção do ser humano".

Desse entendimento, decorre que a sede - principal - dos direitos da personalidade é a Constituição da República Federativa do Brasil de 1988. É dela que decorre implicitamente "a Clausula Geral de Tutela da Personalidade, ao eleger como valor fundamental da República a dignidade humana, que deverá ser protegida e promovida individual e socialmente". (FIÚZA; GAMA, 2009, p. 125). 
Ainda com relação aos aspectos controvertidos dos direitos da personalidade, há alguma divergência terminológica e mesmo conceitual na doutrina com relação a outros direitos que por vezes são relacionados como direitos da personalidade, mas que com ele não se confundem. Nesse campo, pode-se incluir a questão dos direitos da personalidade com relação aos direitos inatos, aos direitos pessoais e aos direitos fundamentais.

Sobre a identidade dos direitos da personalidade como direitos inatos, Bittar (2008, p. 23) entende que por "direitos da personalidade, devem entender-se aqueles que o ser humano tem em face de sua própria condição. São - como anotamos - os direitos naturais, ou inatos, impostergáveis, anteriores ao Estado, e inerentes à natureza livre do homem." Seriam os direitos da personalidade uma nova roupagem para os direitos naturais.

Sobre essa questão, De Cupis (2004, p. 24/25) por sua vez, compreende que os direitos da personalidade "estão vinculados ao ordenamento positivo tanto como os outros direitos subjetivos, uma vez admitido que as ideias dominantes no meio social sejam revestidas de uma particular força de pressão sobre o próprio ordenamento." Por essa razão, não é possível entender os direitos da personalidade como inatos, "entendidos no sentido de direitos relativos, por natureza, à pessoa."

A identificação dos direitos da personalidade com os direitos pessoais também não se justifica. Ascensão (2011) escreve que os termos não se confundem, pois basta se lembrar dos direitos familiares que se enquadram como direitos pessoais que não são direitos da personalidade. Bittar (2008), seguindo o mesmo entendimento, destaca que os direitos da pessoa ou direitos pessoais são previstos desde a antiguidade e consagrados em várias codificações. Os direitos pessoais se prestam a distintas relações que podem alcançar: a) o Estado, ou seus órgãos ou entidades; b) a família e seus componentes e c) a sociedade como um todo ou com algum de seus membros ou grupo.

Com relação à ligação entre direitos da personalidade e direitos fundamentais, Amaral (2003, p. 76) entende que não deve haver distinção 
sobre os termos, pois a personificação do Direito Civil impulsionada pelo reconhecimento constitucional da importância da vida e da dignidade da pessoa humana resultou no "reconhecimento de um novo e importante ramo jurídico, o dos direitos da personalidade, direitos fundamentais ou humanos, que 'constituem o núcleo das constituições dos sistemas jurídicos contemporâneos.'” No mesmo sentido, Pinto (2000, p. 63-64) dispõe que a "essencialidade explica que os direitos da personalidade sejam, em regra, considerados direitos fundamentais."

$\mathrm{Na}$ lição de Bittar (2008, p. 23), na seara pública, temos os direitos fundamentais com o objetivo de proteção do indivíduo contra o Estado, incluindo-se nessa categoria os direitos à vida; à integridade física; às partes do corpo; à liberdade; o direito de ação. "De outro lado, consideram-se direitos da personalidade os mesmos direitos, mas sob o ângulo das relações entre particulares, ou seja, da proteção contra outros homens."

Já aqueles que buscam a diferenciação entre direitos da personalidade e os direitos fundamentais, cuidam da temática sobre a ótica de critérios tidos por formalista, da pertinência da norma e pela ótica da pessoa humana.

Pelo critério formal ou formalista, os direitos fundamentais não se confundem com os direitos da personalidade, pois enquanto aqueles seriam previstos nos artigos $5^{\circ}$ ao 17 da Constituição da República Federativa do Brasil de 1988, independentemente de seu conteúdo, os últimos seriam os direitos estatuídos nos artigos 11 a 21 do Código Civil. (STANCIOLI, 2010).

Tal critério não tem qualquer sustentação uma vez que muitos dos direitos da personalidade previstos nos artigos constitucionais tratam de temas diversos da personalidade da pessoa e, por outro lado, está superada a ideia de que o Código Civil encerra os direitos da personalidade na condição de numerus clausus.

Pelo critério da pertinência da norma, "em uma primeira aproximação, os direitos fundamentais seriam comandos para o 
legislador, ao passo que os direitos da personalidade seriam comandos para o particular". (STANCIOLI, 2010, p. 9).

Tal critério esbarra na questão da possibilidade da aplicação dos direitos fundamentais na esfera privada. A temática tem sido motivo de alguma polêmica que levou à criação de teorias que explicam a chamada eficácia dos direitos fundamentais na órbita do direito privado. (STEINMETZ, 2007). Sobre a questão, Canotilho (2008, p. 191) leciona que:

Haja vista o problema da eficácia dos direitos fundamentais na ordem jurídica privada (Drittwirkung), o problema da privatização de funções e procedimentos públicos, o problema da renúncia a direitos fundamentais, o problema da responsabilidade patrimonial dos entes públicos. Poderemos afirmar, com relativa segurança, que, hoje, um dos temas mais nobres da dogmática jurídica diz respeito às imbricações complexas da irradiação dos direitos fundamentais constitucionalmente protegidos (Drittwirkung) e do dever de proteção de direitos fundamentais por parte do poder público em relação a terceiros (Schutzpflicht) na ordem jurídico-privada dos contratos.

Analisando o tema, Canaris (2003, p. 9) entende que a vinculação dos particulares aos direitos fundamentais seria bastante facilitada se pudessem ser respondidas três questões:

Em primeiro lugar: quem é o destinatário dos direitos fundamentais - apenas o Estado ou também os sujeitos jusprivatistas? Em segundo lugar: de quem é o comportamento objeto do exame realizado com base nos direitos fundamentais - o comportamento de um órgão público ou o de um particular? E, por fim: em que função se aplicam os direitos fundamentais - como proibições de intervenção e direitos de defesa contra o Estado (Abwehrrechte) ou como mandamentos (deveres) de proteção?

Canaris (2003) esclarece que essas questões são o pano de fundo da discussão entre eficácia externa mediata e eficácia externa imediata. A eficácia externa por si considerada quer significar a eficácia 
em relação a terceiros, no caso entre os sujeitos do direito privado. Significando, por sua vez, a expressão "imediata" que os direitos fundamentais teriam como destinatário não só o Estado, mas também o ente privado. Tal vinculação, na acepção de Canaris (2003), contraria a própria concepção do direito privado, nega os séculos de evolução e põe fim à autonomia privada, o que contradiz, em última análise, os próprios direitos fundamentais, razão pela qual essa teoria não pode ser admitida.

Por outro lado, a eficácia externa mediata (CANOTILHO, 2008) admite que o único destinatário dos direitos fundamentais é o Estado, mas simultaneamente reconhece que eles produzem efeitos também nas relações (inter) privadas, e, por tal razão, o Estado é obrigado a proteger o cidadão contra outro cidadão nas suas relações.

Para Tepedino (2006), na era da massificação do consumo e da globalização, pouca serventia têm os direitos fundamentais se as políticas públicas e a atividade econômica ficarem fora do seu espectro de efetividade. Ainda destaca que várias agressões à dignidade humana têm sido registradas devido à insuficiência da legislação infraconstitucional e à tacanha menção que a magistratura tem feito na relação entre direitos fundamentais e direito privado.

Nesse sentido, é valiosa a lição de Sarlet (2000, p. 148) que, analisando detidamente o tema, entende ser evidente que a "dignidade da pessoa não se encontra sujeita apenas às agressões oriundas do Estado, mas também dos particulares, já que, em verdade, pouco importa de quem provém a 'bota no rosto do ofendido"”

Canaris (2003) salienta que na Alemanha essa questão tem tal relevância que existe um recurso constitucional que busca assegurar a inviolabilidade dos direitos fundamentais, pouco importando se o caso vem da esfera civil ou não, uma vez que mesmo as decisões de última instância (Supremo Tribunal Federal) em matéria civil podem ser submetidas à reapreciação daquele Tribunal Constitucional Alemão.

Em julgamento do Recurso Especial 201.819-RJ, realizado no ano de 2006, o Supremo Tribunal Federal, analisando a situação de 
um compositor que foi desligado dos quadros da União Brasileira dos Compositores - (UBC), abordou a questão (BRASIL, 2006). Naquele julgamento, que ficou conhecido como caso UBC, a discussão gravitou em torno da possibilidade de que os direitos fundamentais do compositor afastado fossem efetivos em sua relação com outra pessoa jurídica de direito privado, ou seja, a possibilidade de que os direitos fundamentais fossem aplicados e efetivos nas relações entre privados. Mendes (BRASIL, 2006), em seu voto-vista, entendeu que a discussão sobre a efetividade dos direitos fundamentais nas relações privadas (eficácia horizontal dos direitos fundamentais) é tema complexo e tormentoso, ocupando boa parte do discurso jurídico na Europa e nos Estados Unidos da América. Ainda, segundo ele, mesmo no período do Estado Social os direitos fundamentais tinham nítido caráter de proteção contra os atos do Estado.

O mesmo Ministro afirma também em seu voto vista que a ideia segundo a qual os direitos fundamentais imporiam uma limitação à autonomia das partes é bastante necessária, se se imaginar que o particular teria um campo de atuação livre de qualquer atuação do Estado, podendo-se criar situações contrárias à própria ordem jurídica vigente. Por tal motivo, sustenta que também os direitos privados estão vinculados aos direitos fundamentais. (RIBEIRO, 2011).

Já, Barbosa, em seu voto, entendeu que a aplicação dos direitos fundamentais na órbita privada decorre de vários fatores, entre eles, a supremacia da Constituição e a chamada constitucionalização do direito privado com a queda das barreiras que separam o direito público do privado.

$\mathrm{Na}$ apreciação do caso, o Supremo Tribunal Federal decidiu da seguinte forma: SOCIEDADE CIVIL SEM FINS LUCRATIVOS. UNIÃO BRASILEIRA DE COMPOSITORES. EXCLUSÃO DE SÓCIO SEM GARANTIA DA AMPLA DEFESA E DO CONTRADITÓRIO. EFICÁCIA DOS DIREITOS FUNDAMENTAIS NAS RELAÇÕES PRIVADAS. RECURSO DESPROVIDO. I. EFICÁCIA DOS DIREITOS FUNDAMENTAIS NAS RELAÇÕES PRIVADAS. As 
violações a direitos fundamentais não ocorrem somente no âmbito das relações entre o cidadão e o Estado, mas igualmente nas relações travadas entre pessoas físicas e jurídicas de direito privado. Assim, os direitos fundamentais assegurados pela Constituição vinculam diretamente não apenas os poderes públicos, estando direcionados também à proteção dos particulares em face dos poderes privados (BRASIL, 2006).

Para Gaio Júnior (2009), o Supremo Tribunal Federal reconheceu claramente que os direitos fundamentais podem e devem ser aplicados nas relações entre particulares e incidir não somente no âmbito das relações jurídicas processuais, mas em qualquer ambiente onde esteja presente a violação dos mencionados direitos. Operou-se a quebra de um paradigma, usando a expressão de Kuhn (2009), nas decisões daquele Tribunal Superior, ao permitir, pela primeira, no Brasil, o debate da eficácia dos direitos fundamentais nas relações entre particulares.

Entretanto, inobstante a constatação de que os Direitos Fundamentais têm relevância nas relações privadas e de que, nesse ponto haverá grande coincidência entre os direitos da personalidade e os direitos fundamentais, também é preciso perceber que os direitos fundamentais têm uma amplitude maior e alcançam tema e questões que não dizem respeito aos direitos da personalidade.

Talvez por isso Ascensão (2011, p. 12/13) escreva que há que se considerar as diferenças entre direitos da personalidade e direitos fundamentais, uma vez que os direitos fundamentais "não só não respeitam exclusivamente às pessoas físicas como a sua preocupação básica é a da estruturação constitucional. Demarcam muito em particular a situação dos cidadãos perante o Estado." Por essa razão defende que existem muitos direitos fundamentais que não são direitos da personalidade e, por outro lado, também existem direitos da personalidade que não são direitos fundamentais.

Partindo desse pressuposto, Ascensão (2000) entende que a relação entre direitos da personalidade e direitos fundamentais se dá em função e pela ótica da pessoa humana. 
Stancioli (2010, p. 17) dispõe que "os direitos fundamentais, em suas dimensões objetiva e subjetiva, nada mais são que condições de possibilidade de tutela e livre desenvolvimento da pessoa." Por essa mesma via, Ascensão (2011, p.16) ensina que só pode "ser considerado direito da personalidade aquele direito que encontrar fundamento ético na personalidade humana".

E, por ser assim, segundo Stancioli (2010, p. 25), “há, pois, uma perspectiva bem mais ampla que a imposta pelos fracos limites estatais a que se vinculam os direitos fundamentais". O pensamento do autor revela que o elo que está na essência tanto dos direitos da personalidade como dos direitos fundamentais, e que os identifica, é a tutela e promoção da pessoa humana e é assim que se encontra, por via reflexa, "a verdadeira distinção entre direitos fundamentais e direitos da personalidade, para muito além dos limites territoriais de um dado espaço de soberania."

Talvez por isso, Fiúza e Gama (2009, p. 122) esclareçam que a fonte única, tantos dos direitos da personalidade como dos direitos fundamentais, tem como valor básico a dignidade humana e, desse modo, "não se pode mais falar em proteção da pessoa humana pela via do Direito Público ou do Direito Privado, mas em proteção do ser humano pelo Direito como um todo." Para Perlingieri (2007, p. 155):

A esta matéria não se pode aplicar o direito subjetivo elaborado sobre a categoria do 'ter'. Na categoria do 'ser' não existe dualidade entre sujeito e objeto, porque ambos representam o ser, e a titularidade é institucional, orgânica. Onde o objeto de tutela é a pessoa, a perspectiva deve mudar; torna-se necessidade lógica reconhecer, pela especial natureza do interesse protegido, que é justamente a pessoa a constituir ao mesmo tempo o sujeito titular do direito e o ponto de referência objetivo da relação. A tutela da pessoa não pode ser fracionada em isoladas fattispecie concretas, em autônomas hipóteses não comunicáveis entre si, mas deve ser apresentada como problema unitário, dado o seu fundamento representado pela unidade do valor da pessoa. 
A tutela do ser humano passa a ser à pessoa como um todo, focando a sua preservação e promoção.

\section{Conclusão}

Como visto as chaves da leitura do Direito privado estão na Constituição que por sua vez tem na dignidade da pessoa humana a sua diretriz e fonte normativa e valorativa para a consagração da pessoa como centro normativo do Direito Privado. Outrossim, o cerne do direito privado não está mais no Código Civil ou na própria Constituição, mas sim na proteção da pessoa.

Neste sentir, mais atual, a perspectiva que se deve ter na realização e na tutela dos direitos da personalidade não fica mais adstrita aos fracos limites normativos estabelecidos para os direitos fundamentais. Não se deve mais falar em proteção da pessoa pela via do Direito Privado ou do Direito Constitucional, mas a tutela da pessoa pelo uníssono do Direito.

\section{Referências}

AMARAL, Francisco. O direito civil na Pós-Modernidade. In: FIUZA, César; SÁ, Maria de Fátima Freire de; NAVES, Bruno Torquato de Oliveira. Direito civil: atualidades. Belo Horizonte: Del Rey, 2003. p. 61-77.

ARENDT, Hannah. A condição humana. 10. ed. Rio de Janeiro: Forense Universitária, 2008.

ASCENSÃO, José de Oliveira. Os direitos de personalidade no Código Civil brasileiro. Disponível em: <http://www.fd.ul.pt>. Acesso em: 30 ago. 2011.

BARCELLOS, Ana Paula de. Ponderação, racionalidade e atividade jurisdicional. Rio de Janeiro: Renovar, 2005.

BITTAR, Carlos Alberto; BITTAR FILHO, Carlos Alberto. Direito civil constitucional. 3. ed. São Paulo: RT, 2003. 
BITTAR, Carlos Alberto. Os direitos da personalidade. 7. ed. São Paulo: Forense Universitária, 2008.

BITTAR FILHO, Carlos Alberto. Do dano moral coletivo no atual contexto jurídico brasileiro. Jus Navigandi, Teresina, v.10, n. 559, 17 jan. 2005. Disponível em: <http://jus.com.br/revista/texto/6183>. Acesso em: 10 out. 2011.

BRAGA NETTO, Felipe Peixoto. Direito civil e constituição: desafios e perplexidades de uma aproximação. In: SAMPAIO, José Adércio Leite (Org.). Crise e desafios da constituição. Belo Horizonte: Del Rey, 2004. p. 189-199.

BRASIL. Lei $\mathbf{n}^{\circ} \mathbf{1 0 . 4 0 6}$, de 10 de janeiro de 2002. Institui o Código Civil. Disponível em: <www.planalto.gov.br>. Acesso em: 20 ago. 2011.

BRASIL. Supremo Tribunal Federal. Recurso especial 466.343-SP. Disponível em: <www.stf.gov.br>. Acesso em: 02 jan. 2012.

CANARIS, Claus-Wilhelm. A influência dos direitos fundamentais sobre o direito privado na Alemanha. Revista Jurídica, Porto Alegre, n. 312, p. 07-22, out. 2003.

CANOTILHO, José Joaquim Gomes. Estudos sobre direitos fundamentais. São Paulo: RT, 2008.

CLĖVE, Clèmerson Merlin. A eficácia dos direitos fundamentais sociais. Revista Crítica Jurídica, Curitiba, n.22, p.17-29, jul./dez. 2003. Disponível em: <www.juridicas.unam.mx>. Acesso em: 09 mar. 2009.

COMPARATO, Fábio Konder. Fundamento dos direitos humanos. Disponível em: <www.iea.com.br>. Acesso em: 12 dez. 2008.

COMPARATO, Fábio Konder. A afirmação histórica dos direitos humanos. São Paulo: Saraiva, 2001.

CUPIS, Adriano de. Os direitos da personalidade. Campinas: Romana, 2004.

FIUZA, César; GAMA, André Couto e. Teoria geral dos direitos da personalidade. In: FIUZA, César (Org.). Curso avançado de direito civil. 2. ed. Rio de Janeiro: Forense, 2009. p. 109-127. 
GAIO JÚNIOR, Antônio Pereira. Direito processual civil: teoria geral do processo, processo de conhecimento e recursos. 3. ed. Belo Horizonte: Del Rey, 2009. v. 1.

HIRONAKA, Giselda Maria Fernandes Novaes. Tendências do direito civil no século XXI. In: FIUZA, César; SÁ, Maria de Fátima Freire de; NAVES, Bruno Torquato de Oliveira. Direito civil: Atualidades. Belo Horizonte: Del Rey, 2003. p. 93-114.

JACINTHO, Jussara Maria Moreno. Dignidade humana princípio constitucional. Curitiba: Juruá, 2006.

KANT, Immanuel. Crítica da razão prática. São Paulo: Martin Claret, 2005. (Coleção a obra-prima de cada autor).

KUHN, Thomas S. A estrutura das revoluções científicas. São Paulo: Perspectiva, 2009.

LÔBO, Paulo Luiz Netto. Constitucionalização do direito civil. In: FIUZA, César; SÁ, Maria de Fátima Freire de; NAVES, Bruno Torquato de Oliveira. Direito civil: atualidades. Belo Horizonte: Del Rey, 2003. p. 197-217.

LORENZETTI, Ricardo Luis. Fundamentos do direito privado. São Paulo: RT, 1998.

MORAES, Maria Celina Bodin. Danos à pessoa humana: uma leitura civil-constitucional dos danos morais. Rio de Janeiro: Renovar, 2007.

MORAES, Maria Celina Bodin. A constitucionalização do direito civil e seus efeitos sobre a responsabilidade civil. Direito, Estado e sociedade, Rio de Janeiro, v. 9, n. 29, p. 233-258, jul./dez. 2006.

ORGANIZAÇÃO DAS NAÇÕES UNIDAS. Declaração universal dos direitos do homem. Adotada e proclamada pela resolução $217 \mathrm{~A}$ (III) da Assembleia Geral das Nações Unidas em 10 de dezembro de 1948. Disponível em: <http://www.mj.gov.br>. Acesso em: 29 jan. 2009.

PERLINGIERI, Pietro. Perfis do direito civil: introdução ao direito civil constitucional. 3. ed. Rio Janeiro: Renovar, 2007. 
PINTO, Paulo Mota. Notas sobre o direito ao livre desenvolvimento da personalidade e os direitos de personalidade no direito português. In: SARLET, Ingo Wolfgang (Org.). A constituição concretizada: construindo pontes com o púbico e o privado. Porto Alegre: Livraria do Advogado, 2000. p. 61-83.

PIOVESAN, Flávia. A incorporação, a hierarquia e o impacto dos tratados de proteção de direitos humanos no direito brasileiro: 0 sistema interamericano de direitos humanos e o direito brasileiro. São Paulo: Revista dos Tribunais, 2000.

PIOVESAN, Flávia. Direitos humanos e justiça internacional: um estudo comparativo dos sistemas regionais europeu, interamericano e africano. São Paulo: Saraiva, 2006.

RIBEIRO, Wesllay Carlos. A eficácia dos direitos fundamentais nas relações privadas. In: GAIO JÚNIOR, Antônio Pereira. Direito processual em movimento. Curitiba: CRV, 2011. p. 191-210

SANTOS, Boaventura de Sousa. A gramática do tempo para uma nova cultura política. 2. ed. São Paulo: Cortez, 2008.

SARLET, Ingo Wolfgang. Dignidade da pessoa humana e direitos fundamentais na Constituição Federal de 1988. Porto Alegre: Livraria do Advogado, 2007.

SARMENTO, Daniel. Direitos fundamentais e relações privadas. Rio Janeiro: Lumen Juris, 2008.

SILVA, José Afonso da. Poder constituinte e poder popular: estudos sobre a constituição. São Paulo: Malheiros, 2007.

STANCIOLI, Brunello. Renúncia ao exercício de direitos da personalidade ou como alguém se torna o que quiser. Belo Horizonte: Del Rey, 2010.

STEINMETZ, Wilson. Princípio da proporcionalidade e atos de autonomia privada restritivos de direitos fundamentais. Interpretação constitucional. São Paulo: Malheiros, 2007. 
STRECK, Lenio Luiz. Jurisdição constitucional e hermenêutica: uma nova crítica do direito. 2. ed. Rio de Janeiro: Forense, 2004.

TEPEDINO, Gustavo. A constitucionalização do direito civil: perspectivas interpretativas diante do novo código. In: FIUZA, César; SÁ, Maria de Fátima Freire de; NAVES, Bruno Torquato de Oliveira. Direito civil: Atualidades. Belo Horizonte: Del Rey, 2003. p. 115-130.

TEPEDINO, Gustavo. A incorporação dos direitos fundamentais pelo ordenamento brasileiro: sua eficácia nas relações jurídicas privadas. Revista Jurídica, Porto Alegre, n. 341, p. 11-26, mar. 2006.

TRAVESSONI, Alexandre. Pós-positivismo jurídico. In: TRAVESSONI, Alexandre (Org.). Dicionário de teoria e filosofia do direito. São Paulo: LTr, 2011. p. 319-324.

Recebido em: 21/05/14 Aprovado em: 06/06/14 